\title{
A CLINICAL STUDY OF SENSORINEURAL HEARING LOSS IN DIABETIC PATIENTS
}

\author{
Vinayak1 $^{1}$, Sheila Raman Kutty², Balakrishnan Edacheriyan'3 ${ }^{3}$ Sandeep 4 \\ ${ }^{1}$ Resident, Department of ENT, Academy of Medical Sciences, Pariyaram. \\ ${ }^{2}$ Associate Professor, Department of ENT, Academy of Medical Sciences, Pariyaram. \\ 3 Professor, Department of ENT, Academy of Medical Sciences, Pariyaram. \\ ${ }^{4}$ Resident, Department of ENT, Academy of Medical Sciences, Pariyaram.
}

\begin{tabular}{l}
\hline ABSTRACT \\
\hline BACKGROUND \\
Evaluation of hearing loss with diabetic control. The aim of this study was to know the prevalence of sensorineural hearing loss in \\
diabetic patients attending medicine outpatient department and to know the association between the duration of diabetes mellitus \\
and severity of sensorineural hearing loss.
\end{tabular}

Setting and Design- The study was done at a tertiary care hospital and a hospital based cross sectional study design was employed.

\section{MATERIALS AND METHODS}

Two hundred known diabetic patients who satisfied the selection criteria and consented were included in the study. Sample technique used was consecutive sampling. Data collection technique and tools were through a detailed ENT examination, fasting and postprandial blood sugar estimation and pure tone audiometry.

Statistical Analysis- Statistical analysis was performed using the Statistical Package for Social Sciences (SPSS). Data collected was analysed statistically using descriptive statistical methods like frequencies, percentage, mean and standard deviation. Results were presented in the form of both tables and graphs. An inferential statistical tool like chi-square test was used. The test was considered significant at $\mathrm{p}<0.05$.

\section{RESULTS}

The prevalence of sensorineural hearing loss in the study group was 34.5\%. Severity of sensorineural hearing loss was high among older age group. Severity of sensorineural hearing loss was high among the cases with greater duration of DM. The prevalence of sensorineural hearing was more in patients having uncontrolled diabetic status $(94.6 \%)$ compared to patients having controlled diabetic status $(20.9 \%)$.

\section{CONCLUSION}

The prevalence of sensorineural hearing in diabetic patients is $34.5 \%$. It was found that greater the duration of diabetes greater is the prevalence of sensorineural hearing loss. In less than 5 years duration group, prevalence was $10.6 \%$. In 5 to 10 years duration group, prevalence was $38.6 \%$. In 10 to 15 years duration group, prevalence was $69.2 \%$. In more than 15 years duration group, it was $78.9 \%$. Severity of sensorineural hearing loss was also high among the cases with greater duration of diabetes mellitus. The prevalence of sensorineural hearing loss was more in patients having uncontrolled diabetic status (94.6\%) compared to patients having controlled diabetic status (20.9\%). Severity was also high among uncontrolled diabetic group.

\section{KEYWORDS}

Diabetes Mellitus, Pure Tone Audiometry. Sensorineural Hearing Loss.

HOW TO CITE THIS ARTICLE: Vinayak, Kutty SR, Edacheriyan B, et al.A clinical study of sensorineural hearing loss in diabetic patients. J. Evolution Med. Dent. Sci. 2016;5(87):6469-6475, DOI: 10.14260/Jemds/2016/1463

\section{BACKGROUND}

Diabetes mellitus is a syndrome of chronic hyperglycaemia due to relative deficiency of insulin, resistance to insulin, or both. Its prevalence has been estimated to be more than 285 million people worldwide and 51 million in India. (1) It produces complications which are vascular and/or neurologic, though there is disagreement among researchers regarding

Financial or Other, Competing Interest: None.

Submission 25-09-2016, Peer Review 19-10-2016,

Acceptance 25-10-2016, Published 28-10-2016.

Corresponding Author:

Dr. Sheila Raman Kutty,

Department of ENT, Academy of Medical Sciences,

Pariyaram, Kannur-670503

Kerala.

E-mail: sheelaent@yahoo.com

DOI: $10.14260 /$ jemds/2016/1463

(c) $($ ) $\$$ the existences of hearing loss secondary to Diabetes Mellitus. (24) There is some evidence that elderly diabetic patients have progressive bilateral sensorineural hearing impairment with gradual onset predominantly affecting the higher frequencies.(2)

EI-Tabal et al reported that the hearing threshold in diabetic patients and controls in all age groups had no significant differences except for high frequencies that is > $4000 \mathrm{~Hz}$ in the age group of 40 years or older.(5) In addition, it has been suggested that the severity of diabetes mellitus or the serum glucose level may be related to hearing loss, few studies have examined the potential link between hearing loss and the severity of diabetes.

Panchu found that all the frequencies (250 to 8,000 Hz) were affected in poorly controlled diabetics, that is glycosylated haemoglobin $(\mathrm{HbA} 1 \mathrm{c})>8 \%$, while examining the 
auditory acuity in type 2 diabetes mellitus in an Indian population. $\left.{ }^{6}\right)$

Asma et al failed to establish any association between the type of treatment given and the effect on hearing thresholds in their study on conventional oral hypoglycaemic agents versus insulin therapy on pure tone average.(7)

In a study conducted by Sheetal Krishnappa et al (2015), prevalence of hearing loss was high in type 2 diabetic patients (73\%). Bilaterally symmetrical progressive SNHL with right sloping curve was seen in both diabetics as well as nondiabetics, with hearing loss noted at all frequencies, but significantly in higher frequencies in diabetics. Hearing threshold increased linearly with increase in age. No significant difference was seen in hearing threshold between diabetic males and females.

However, a significant relationship was observed between HbA1c, blood sugar levels and severity of hearing loss. The severity increased as the duration of diabetes increased.(8) In a study conducted by Hamid Abdul Qaiyum et al (2015) in 50 diabetics and 50 non-diabetics, the pure tone audiometry test revealed that $13(26 \%)$ diabetic cases were having mildto-moderate sensorineural hearing loss as against $4(8 \%)$ in nondiabetic controls $(\mathrm{p}<0.05)$. It is concluded that the diabetic patients have significantly high incidence of sensorineural hearing loss when compared to non-diabetic control group of comparable age.(9)

In a study conducted by Ashish C Agarwal et al (2015) in 40 diabetic patients, majority of the patients had bilateral sensorineural hearing loss ranging in severity from minimal to mild degree. Median pure tone average (PTA) values were less in patients with good glycaemic status as compared to those with poor glycaemic status.

OAEs were absent in $30 \%$ of the subjects. Age had a contributing effect on raising the hearing threshold but gender and duration of diabetes did not show such an effect.(10)

The current study aimed to document the prevalence of sensorineural hearing loss in diabetes mellitus and the association between the duration of diabetes mellitus and severity of sensorineural hearing loss.

\section{MATERIALS AND METHODS}

A cross - sectional study was carried out from March 2014 to 2015 on 200 consecutive diabetic patients visiting the outpatient department of medicine of a tertiary hospital. Subjects included in the study were diabetic patients (type 1 and Type 2) of either gender.

Inclusion criteria included diabetic patients in the age between 30 to 55 years and patients willing to undergo the investigations. Exclusion criteria included patients outside the age range of 30-55 years, Patients not willing to undergo pure tone audiometry testing, patients with a history of ear discharge, perforated tympanic membrane or any chronic ear discharge, history of intake of ototoxic drugs continuously for more than 6 months, prolonged history of exposure to noise (e.g. Industrial workers) were excluded from the study. Patients with history of head injury and hearing loss due to viral infections or ear surgery were not included in this study. The patients who were diagnosed to have diabetes mellitus according to the criteria given by the American Diabetes Association(11) were included as a part of the study.
An otoscopic examination was performed by a qualified ENT doctor prior to selection of the subject. Clearance from the Institutional Ethics Committee (IEC) was obtained prior to the start of the study. Informed written consent was taken from all the subjects. After consent the demographic data, clinical characteristics and audiological symptoms were noted down for further analysis. All the subjects underwent biochemical and routine urine investigations such as postprandial blood (PPBS), fasting blood sugar (FBS), serum urea and creatinine and urine for sugar, protein, ketones, and microalbuminuria was obtained prior to the start of the study.

The audiological investigations were performed by a qualified audiologist at our institute. Pure tone audiometry was carried out on all the subjects in a sound treated room. PTA was carried out for the estimation of hearing thresholds using a double channel GSI clinical audiometer. Pure tone thresholds were obtained at an octave between frequencies of 250 and $8000 \mathrm{~Hz}$ for air conduction and 250 and $4000 \mathrm{~Hz}$ for bone conduction.

Statistical package for social sciences (SPSS) was used to analyse the data. The data thus obtained was analysed statistically and presented in the form of tables, figures, graphs and diagrams wherever necessary. An inferential statistical tool like chi-square test was used. The test was considered significant at $\mathrm{p}<0.05$.

\section{OBSERVATIONS AND RESULTS:}

The study of Prevalence of Sensorineural hearing loss in 200 diabetic patients from March 2014 to March 2015.

The main parameters that were studied are as follows:

1. Age and Sex distribution of the subjects.

2. Prevalence of SNHL among diabetics.

3. SNHL and Age of the subjects.

4. Severity of SNHL and Age of the subjects.

5. SNHL and Sex of the subjects.

6. SNHL and Duration of diabetes.

7. Severity of SNHL and Duration of DM.

8. SNHL and Status of diabetes.

9. Severity of SNHL and Status of DM.

\section{Age and Sex Distribution of the Cases}

Among the 200 total cases studied, 124 were males and 76 were females. The subjects involved in this study were divided into 3 groups, A, B and C. Among the group A (30 to 38 years), there were 67 cases ( 41 males +26 females). Among the group B (39 to 46 years), there were 66 cases ( 48 males +18 females). Among the group C (47 to 55 years), there were 67 cases (35 males +32 females).

Mean age was 42.51 years with standard deviation 7.49 years. M:F ratio was 1.63:1.

\begin{tabular}{|c|c|c|c|c|}
\hline Age Group & Age Group & Males & Females & Total \\
\hline A & 30 to 38 years & 41 & 26 & 67 \\
\hline B & 39 to 46 years & 48 & 18 & 66 \\
\hline C & 47 to 55 years & 35 & 32 & 67 \\
\hline \multicolumn{5}{|c|}{ Table 1. Age and Sex Distribution } \\
\hline & Tabl & $\mathbf{1 2 4}$ & $\mathbf{7 6}$ & $\mathbf{2 0 0}$ \\
\hline
\end{tabular}




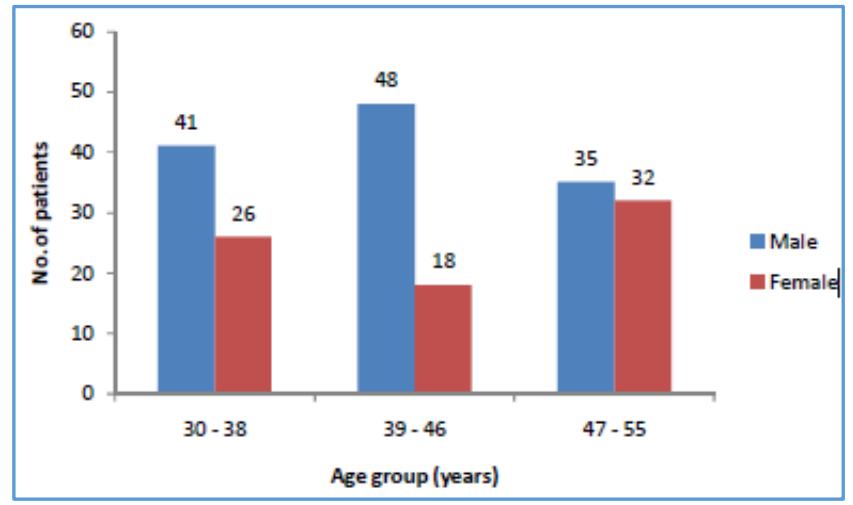

Graph 1. Age and Sex Distribution

\section{Prevalence of Sensorineural Hearing Loss}

In our study of 200 patients with diabetes mellitus, 69 patients (34.5\%) were found to have SNHL. 95\% Confidence interval for prevalence $=31.1 \%, 37.9 \%$.

\begin{tabular}{|c|c|c|}
\hline Type of subjects & No. of Subjects & \% \\
\hline SNHL & 69 & $34.5 \%$ \\
\hline Normal & 131 & $65.5 \%$ \\
\hline Total & 200 & $100 \%$ \\
\hline \multicolumn{2}{|c|}{ Table 2. Prevalence of SNHL } \\
\hline
\end{tabular}

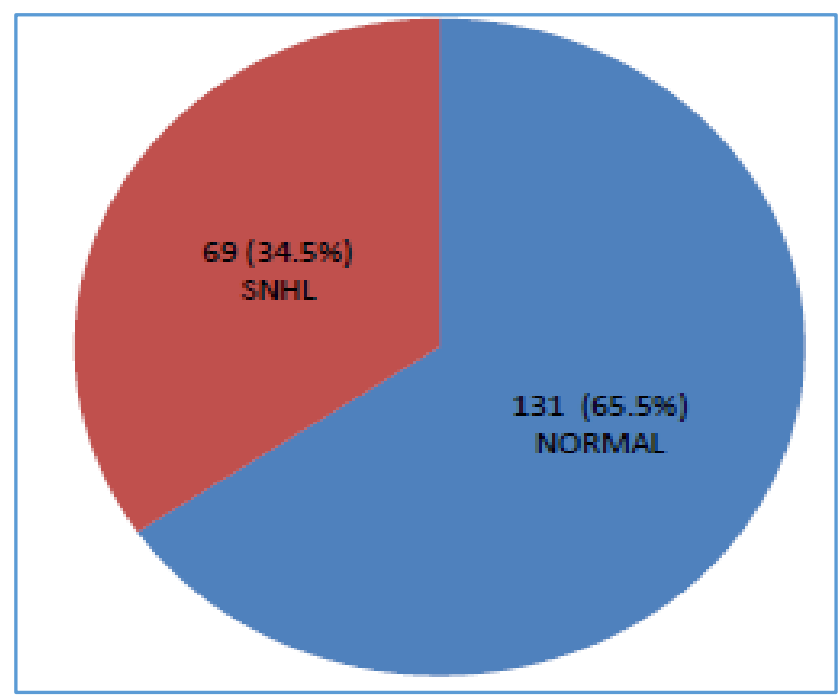

Graph 2. Prevalence of SNHL

SNHL and Age of the Subject

The subjects involved in the study were divided in to three groups as group A (31-38 years of age), group B (39-46 years of age) and group $C$ (46-55 years of age). In group $A$, there were 67 patients of which $10(14.9 \%)$ had SNHL. In group B, there were 66 patients of which 20 had SNHL (30.3\%). In group C, there were 67 patients of which 39 (58.2\%) had SNHL. On statistical analysis using chi-square test, age is obtained as a significant factor responsible for SNHL in diabetics ( $p$ value $<0.001$ )

\begin{tabular}{|c|c|c|c|c|}
\hline $\begin{array}{c}\text { Group } \\
\text { P }\end{array}$ & $\begin{array}{c}\text { Age in } \\
\text { Years }\end{array}$ & $\begin{array}{c}\text { Total } \\
\text { Subjects }\end{array}$ & $\begin{array}{c}\text { Subjects } \\
\text { with SNHL }\end{array}$ & $\%$ \\
\hline A & $30-38$ & 67 & 10 & $14.9 \%$ \\
\hline B & $39-46$ & 66 & 20 & $30.3 \%$ \\
\hline C & $47-55$ & 67 & 39 & $58.2 \%$ \\
\hline \multicolumn{7}{|c}{ Table 3. SNHL and Age Distribution of Cases } \\
\hline
\end{tabular}

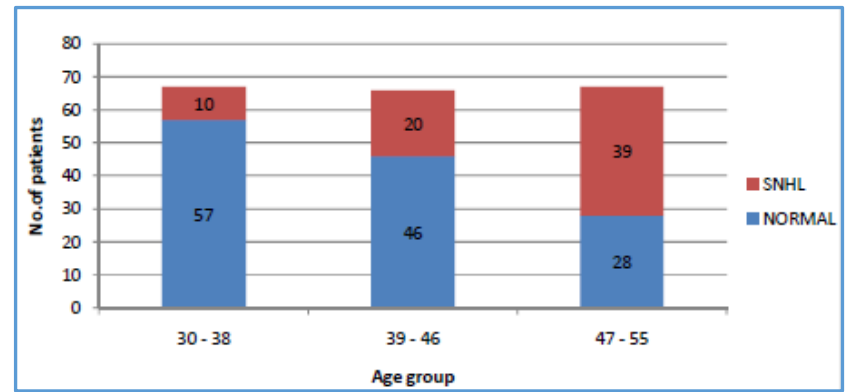

Graph 3. SNHL and Age Distribution of Cases

\section{Severity of SNHL and Age of the Subject}

Among the group A (30 - 38 years of age), 57 patients (85.1\%) were having normal hearing out of total 67 cases. 10 cases were having mild SNHL (14.9\%). Higher grades of hearing loss were not present in this group. Among the age group B (3946 years of age), 46 cases $(69.7 \%)$ were having normal hearing out of total 66 cases. 17 cases were having mild SNHL (25.8\%). 3 cases were having moderate SNHL (4.5\%). Other higher grades of SNHL cases were not seen in this group. Among the group C (47-55 years of age), 28 cases $(41.8 \%)$ out of total 67 cases were normal. 14 cases were having mild SNHL (20.9\%), 12 cases were having moderate SNHL (17.9\%), 11 cases were having moderately severe SNHL (16.4\%), 2 cases were having severe SNHL (3.0\%). No cases were having profound hearing loss. So the severity of SNHL is higher in older patients.

\begin{tabular}{|c|c|c|c|c|c|}
\hline $\begin{array}{c}\text { Age } \\
\text { Group }\end{array}$ & $\begin{array}{c}\text { Total } \\
\text { Cases }\end{array}$ & Normal & $\begin{array}{c}\text { Mild } \\
\text { SNHL }\end{array}$ & $\begin{array}{c}\text { Moderate } \\
\text { SNHL }\end{array}$ & $\begin{array}{c}\text { Severe } \\
\text { SNHL }\end{array}$ \\
\hline A & 67 & $\begin{array}{c}57 \\
(85.1 \%)\end{array}$ & 0 & 0 & 0 \\
\hline B & 66 & $\begin{array}{c}17 \\
(69.7 \%)\end{array}$ & $\begin{array}{c}3 \\
(4.5 \%)\end{array}$ & 0 & 0 \\
\hline C & 67 & $\begin{array}{c}28 \\
(41.8 \%)\end{array}$ & $\begin{array}{c}14 \\
(20.9 \%)\end{array}$ & $\begin{array}{c}11 \\
(16.4 \%)\end{array}$ & $2(3 \%)$ \\
\hline \multicolumn{6}{|c|}{ Table 4. Severity of SNHL and Age of the Subject } \\
\hline
\end{tabular}

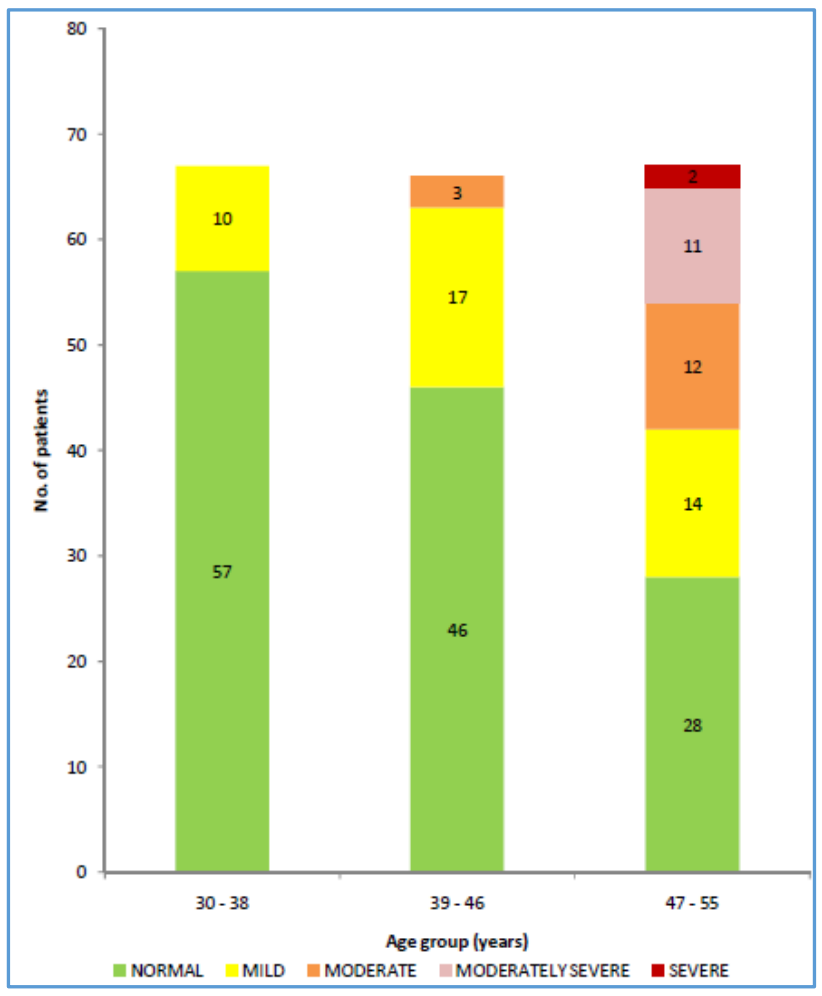

Graph 4. Table 4. Severity of SNHL and Age of the Subject 


\section{SNHL and Sex of the Subject}

In our study out of 200 subjects, there were 124 males and 76 females. In male population, 39 (31.5\%) had SNHL and in female population 30 (39.5\%) had SNHL. On statistical analysis with chi-square test, it was found that sex has no effect on SNHL in diabetics.

\begin{tabular}{|c|c|c|c|}
\hline Sex & No. of Cases & Case with SNHL & Prevalence \\
\hline Male & 124 & 39 & $31.5 \%$ \\
\hline Female & 76 & 30 & $39.5 \%$ \\
\hline Total & $\mathbf{2 0 0}$ & $\mathbf{6 9}$ & $\mathbf{3 4 . 5 \%}$ \\
\hline \multicolumn{3}{|c|}{ Table 5. Sex Distribution of Cases } \\
\hline
\end{tabular}

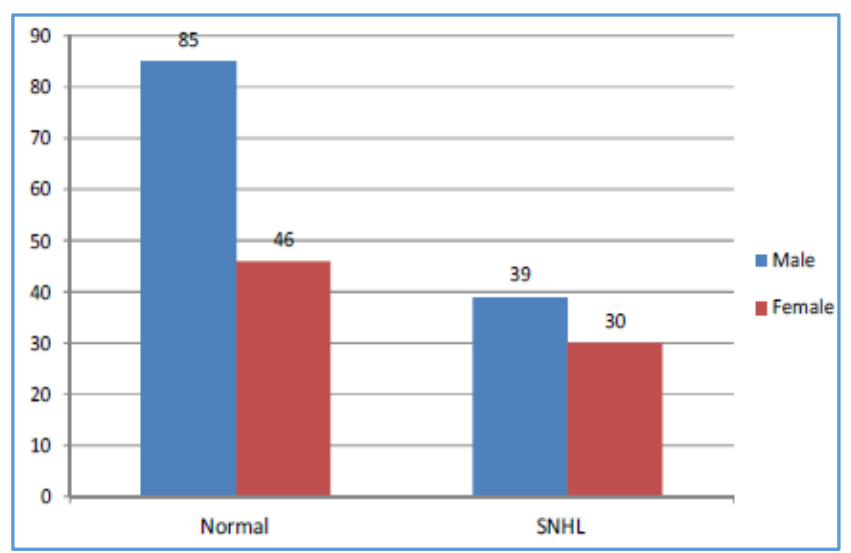

Graph 5. Sex Distribution of Cases

\section{SNHL and Duration of Diabetes}

In our study, the subjects were divided in to 4 groups on the basis of duration of diabetes. It is found that greater the duration of diabetes greater is the prevalence of SNHL. The duration of DM is a significant factor responsible for SNHL in diabetics (chi-square test, $\mathrm{p}$ value $<0.001$ ).

\begin{tabular}{|c|c|c|c|}
\hline $\begin{array}{c}\text { DM Duration } \\
\text { Group }\end{array}$ & Subjects & $\begin{array}{c}\text { Subjects with } \\
\text { SNHL }\end{array}$ & Prevalence \\
\hline$<5$ years & 85 & 9 & $10.6 \%$ \\
\hline 5-10 years & 70 & 27 & $38.6 \%$ \\
\hline 10-15 years & 26 & 18 & $69.2 \%$ \\
\hline$>15$ years & 19 & 15 & $78.9 \%$ \\
\hline \multicolumn{2}{|c|}{ Table 6. SNHL and Duration of Diabetes } \\
\hline
\end{tabular}

\begin{tabular}{|c|c|c|c|}
\hline $\begin{array}{c}\text { DM Duration } \\
\text { Group }\end{array}$ & Subjects & $\begin{array}{c}\text { Subjects with } \\
\text { SNHL }\end{array}$ & Prevalence \\
\hline$<5$ years & 85 & 9 & $10.6 \%$ \\
\hline $5-10$ years & 70 & 27 & $38.6 \%$ \\
\hline $10-15$ years & 26 & 18 & $69.2 \%$ \\
\hline$>15$ years & 19 & 15 & $78.9 \%$ \\
\hline \multicolumn{2}{|c}{ Table 6. SNHL and Duration of Diabetes } \\
\hline
\end{tabular}

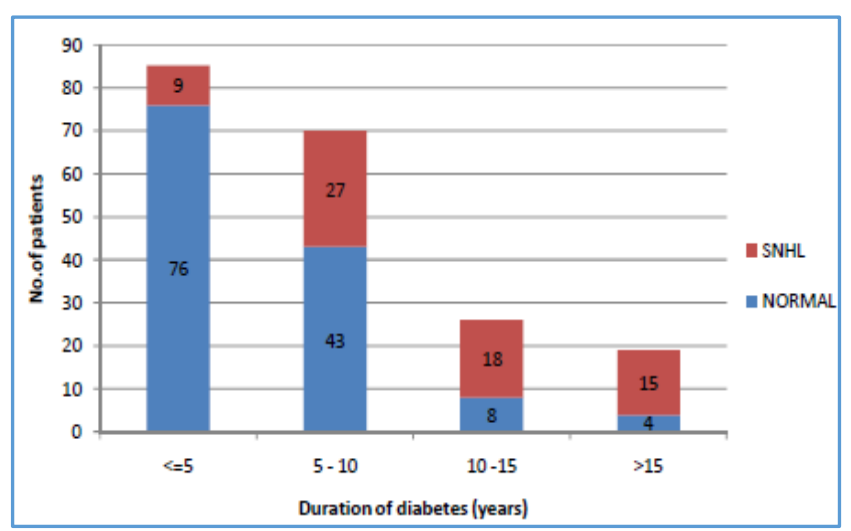

Graph 6. SNHL and Duration of Diabetes

\section{Severity of SNHL and Duration of DM}

Among the cases with duration of DM $<5$ years, $76(89.4 \%)$ cases were having normal hearing out of total 85 cases, 8 cases were having mild SNHL (9.4\%) and 1 case was having moderate SNHL (1.2\%). Among the cases with duration of DM 5- 10 years, 43 cases (61.4\%) were having normal hearing out of 70 cases, 25 cases were having mild SNHL (35.7\%) and 2 cases were having moderate SNHL (2.9\%). Among the cases with duration of DM 10-15 years, 8 cases (30.8\%) were having normal hearing out of total 26 cases, 6 cases were having mild SNHL (23.1\%), 6 cases were having moderate SNHL $(23.1 \%)$ and 6 cases were having moderately severe SNHL (23.1\%). Among the cases with duration of DM >15 years, 4 cases (21.1\%) were having normal hearing out of total 19 cases, 2 cases were having mild SNHL $(10.5 \%), 6$ were having moderate SNHL (31.6\%), 5 cases were having moderately severe SNHL (26.3\%) and 2 cases were having severe SNHL (10.5\%).

\begin{tabular}{|c|c|c|c|c|c|c|}
\hline DM Duration & Total Cases & Normal & Mild SNHL & Moderate SNHL & Moderate Severe SNHL & Severe SNHL \\
\hline$<5$ years & 85 & $76(89.4 \%)$ & $8(9.4 \%)$ & $1(1.2 \%)$ & 0 & 0 \\
\hline $5-10$ years & 70 & $43(61.4 \%)$ & $\begin{array}{c}25 \\
(35.7 \%)\end{array}$ & $2(2.9 \%)$ & 0 & 0 \\
\hline $10-15$ years & 26 & $8(30.8 \%)$ & $6(23.1 \%)$ & $6(23.1 \%)$ & $6(23.1 \%)$ & 0 \\
\hline$>15$ years & 19 & $4(21.1 \%)$ & $2(10.5 \%)$ & $6(31.6 \%)$ & $5(26.3 \%)$ & $2(10.5 \%)$ \\
\hline \multicolumn{78}{|c|}{ Table 7. Severity of SNHL and Duration of DM } \\
\hline
\end{tabular}




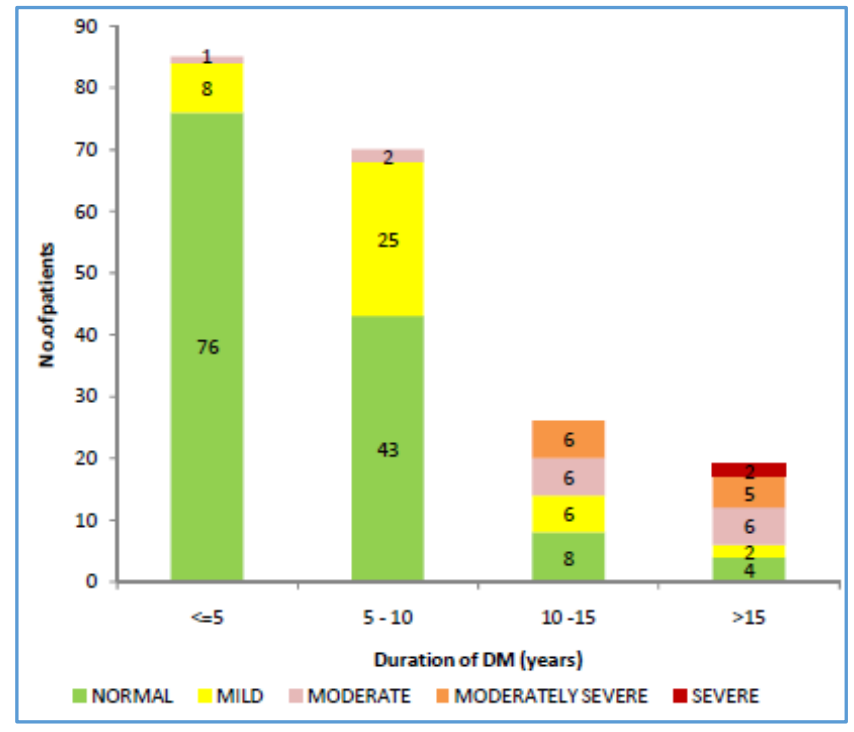

Graph 7. Severity of SNHL and Duration of DM

\section{SNHL and Status of Diabetes}

In our study among the 200 subjects, 37 had uncontrolled diabetes and 163 had controlled diabetes. Among the uncontrolled, 35 (94.6\%) had SNHL. Among controlled group, $34(20.9 \%)$ had SNHL. On statistical analysis, the status of DM is a significant factor responsible for SNHL in diabetics (chisquare test, $\mathrm{p}$ value $<0.001$ ).

\begin{tabular}{|c|c|c|c|}
\hline DM Status & Cases & Cases of SNHL & Prevalence \\
\hline Controlled & 163 & 34 & $20.9 \%$ \\
\hline Uncontrolled & 37 & 35 & $94.6 \%$ \\
\hline \multicolumn{3}{|c|}{ Table 8. SNHL and Status of Diabetes } \\
\hline
\end{tabular}

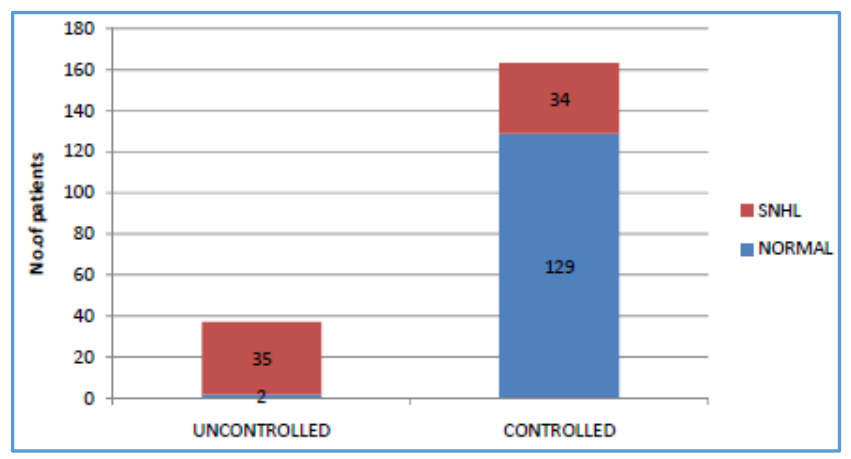

Graph 8. SNHL and Status of Diabetes

\section{Severity of SNHL and Status of Diabetes}

Out of total 200 cases, 163 cases were having controlled diabetic status and 37 cases were having uncontrolled diabetic status. Among the 163 cases of controlled DM, 129 cases (79.1\%) were having normal hearing status, 30 cases were having MILD SNHL (18.4\%) and 4 cases were having moderate SNHL (2.5\%). Among the 37 cases of uncontrolled DM, 2 cases (5.4\%) were having normal hearing, 11 cases were having mild SNHL (29.7\%), 11 cases were having moderate SNHL (29.7\%), 11 cases were having moderately severe SNHL (29.7\%) and 2 cases (5.4\%) were having severe SNHL. More severe type of SNHL is seen among uncontrolled diabetic group.

\begin{tabular}{|c|c|c|c|c|c|c|}
\hline DM Status & Total Cases & Normal & Mild SNHL & Moderate SNHL & $\begin{array}{c}\text { Moderate } \\
\text { Severe SNHL }\end{array}$ & $\begin{array}{c}\text { Severe } \\
\text { SNHL }\end{array}$ \\
\hline Controlled & 163 & $129(79.1 \%)$ & $30(18.4 \%)$ & $4(2.5 \%)$ & 0 & 0 \\
\hline Uncontrolled & 37 & $2(5.4 \%)$ & $11(29.7 \%)$ & $11(29.7 \%)$ & $11(29.7 \%)$ & $2(5.4 \%)$ \\
\hline \multicolumn{7}{|r|}{ Table 9. Severity of SNHL and Status of Diabetes } \\
\hline
\end{tabular}

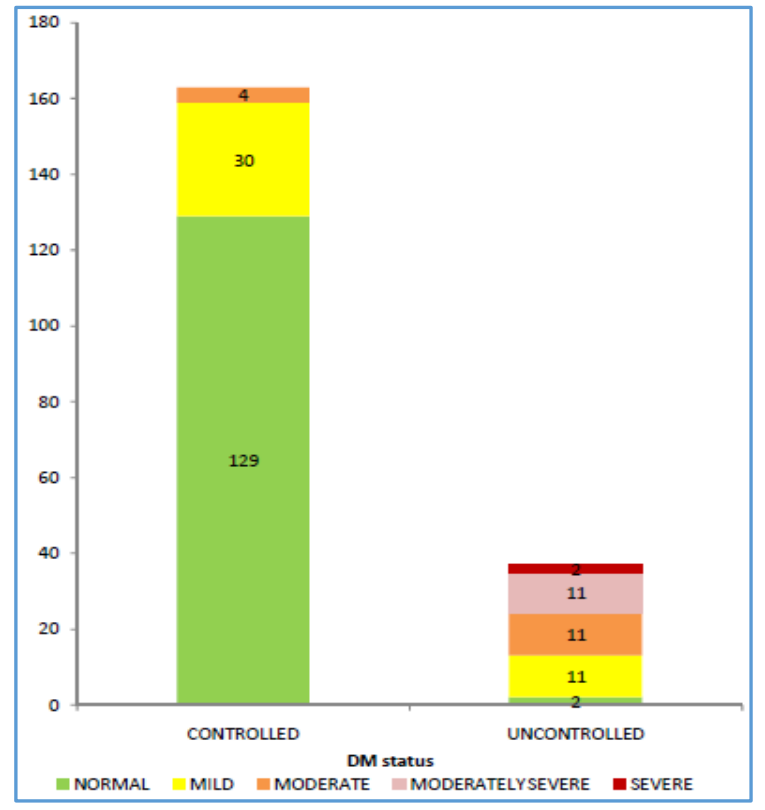

Graph 9. Severity of SNHL and Status of Diabetes

\section{Distribution of Cases}

Age and Sex Distribution

In our study, cases belong to age between 30 and 55 years and the mean age was 42.51 years, S.D. $=7.49$ years.

Among the 200 patients, there were 124 males and 76 females. $\mathrm{M}: \mathrm{F}$ ratio was 1.63:1.

\section{Prevalence of SNHL}

In our study, among 200 type 2 diabetic patients, prevalence of SNHL was $34.5 \%$. The results approximate to the study conducted by Colonel P C Chamyal.(12) in which hearing loss mild to moderate was detected in $40 \%$ of diabetics. In a study conducted by Venkata Kakarlapudi,(13) prevalence of SNHL in diabetic group was $13.1 \%$. In a study conducted by Ashish C Agarwal,(10) $67.5 \%$ of DM individuals had SNHL. There is wide variation of results regarding the prevalence of SNHL in diabetics due to different inclusion and exclusion criteria, methodology and diagnostic approaches.

\section{Type of SNHL}

The SNHL was bilaterally symmetrical and progressive. It mainly affected higher frequencies. 
This result is supported by studies of Colonel $\mathrm{P} C$ Chamyal.(12) Cullen R and Kurien M.(3) According to Sheetal Krishnappa et $\mathrm{al},(8)$ there was bilateral progressive sensorineural hearing loss with right sloping curve in both diabetics as well as controls but with significantly $(\mathrm{P}<0.001)$ higher loss in diabetics (at $4 \mathrm{KHz}$ and $8 \mathrm{KHz}$ ).

\section{SNHL and Age of the Subjects}

On correlating sensorineural hearing loss in three age groups, the prevalence of SNHL was more pronounced in the 47-55 years age group (58.2\%) than other groups. 39-46 years age group showed a prevalence of $30.3 \%$ and 30 to 38 years age group showed a prevalence of $14.9 \%$. Age is obtained as a significant factor (chi square test, $\mathrm{p}$ value $<0.001$ ). In our study, the severity of SNHL was also more pronounced among older age group.

Ashish Agarwal et al(10) reported that age had a contributing effect on raising the hearing threshold in diabetic patients.

According to Sheetal Krishnappa et al(8), the degree of hearing loss increased with age.

\section{SNHL and Sex of the Subject}

In our study, $31.5 \%$ of males and $39.5 \%$ of females were having SNHL. On statistical analysis with chi-square test, it was found that sex has no effect on SNHL in diabetics.

Ashish C Agarwal et al(10) noted that gender did not have an effect on hearing status of diabetic patients.

According to Cullen and Cinnamond(3), male patients with diabetes had worse hearing than females patients with diabetes.

\section{SNHL and Duration of DM}

There is a strong correlation between the duration of diabetes and SNHL in our study. Those who are having more than 15 years of DM had a high prevalence of SNHL (78.9\%). In the group with duration of $\mathrm{DM}<5$ yrs., prevalence is only $10.6 \%$. The duration of DM is a significant factor responsible for SNHL in diabetics (chi-square test, $p$ value<0.001). In our study, it was found that the severity of hearing loss was proportional to the duration of DM.

According to Sheetal Krishnappa et al(8), there was $63 \%$ incidence of hearing loss in $<10$ years of duration of diabetes as compared to $85 \%$ in $>10$ years of duration. Further, as duration progressed, the severity of hearing loss also increased in most of the cases.

Ashish C Agarwal et al(10) noted that duration of DM did not have an effect on hearing status of diabetic patients.

\section{SNHL and Status of DM}

In our study, there is a high prevalence of SNHL among uncontrolled diabetics (94.6\%) compared to controlled diabetics (20.9). The control status of DM is a significant factor responsible for SNHL in diabetics (chi-square test, $p$ value $<0.001$ ).

The severity of SNHL was also high among uncontrolled DM group compared to controlled DM group.

Ashish C Agarwal et al (10) noted that median pure tone average (PTA) values were less in patients with good glycaemic status as compared to those with poor glycaemic status.

\section{DISCUSSION}

The relationship between diabetes mellitus and sensory neural hearing loss is complex and under debate since many years supported by the bulk of conflicting literature. The crux about the effect of diabetes in SNHL lies centred around the cochlea and the neural pathways, which has been studied throughout the years in relation to age, sex, duration of DM and glycaemic levels.

Overall, in this study, it is seen that $34.5 \%$ of diabetic individuals had sensorineural hearing loss. The sensorineural hearing was bilaterally symmetrical and progressive and affected higher frequency. Similar findings were also noted in other studies. $(3,8,12)$

In the study conducted by Colonel P C Chamyal, sensorineural hearing loss was seen in $40 \%$ diabetics ranging from mild to moderate in nature.(12) Similar study conducted by Venkata Kakarlapudi, the prevalence of SNHL in diabetic group was 13.1\%.(13) Ashish C Agarwal et al in a study conducted in 2014 found that that $67.5 \%$ had sensorineural hearing loss.(10) There is wide variation of results regarding the prevalence of SNHL in diabetics due to different inclusion and exclusion criteria, methodology and diagnostic approaches.

In the current study, it was seen that the younger age group did have better hearing thresholds as compared to those in the older age group. The severity of sensorineural hearing loss was also more pronounced among older age group. Other studies also showed that age had a contributing effect on raising the hearing threshold in diabetic patients. $(10,8)$

Studies on diabetes mellitus and hearing loss in the past have indicated evidence of elderly diabetic patients having a gradual onset of progressive , bilateral , sensorineural hearing impairment predominantly affecting the higher frequencies.(12) Suggested pathogenesis for this diabetes mellitus associated sensorineural hearing loss has included cochlear microangiopathy, hyperglycaemia of cerebrospinal fluid or perilymph, auditory neuropathy and diabetic encephalopathy even though there is disagreement among researchers regarding the existence of hearing loss secondary to diabetes. $(3,4)$ This necessitates caring out screening for hearing loss as a routine procedure for every individual diagnosed with diabetes mellitus. Apart from exhibiting obvious hearing loss, these individuals exhibit central auditory processing deficits or auditory neuropathy as stated above which results in speech understanding difficulties even the hearing thresholds may be within normal limits.

This study also tried to understand the relationship of diabetes mellitus with factors as age, gender and duration of diabetes and the effect on the hearing thresholds. Severe type of sensorineural hearing loss was seen in this study among uncontrolled diabetic group. In our study, there is a high prevalence of SNHL among uncontrolled diabetics (94.6\%) compared to controlled diabetics. Well-controlled diabetics has a better hearing acuity than poorly controlled diabetics. In the present study, it was found that the severity of hearing loss was proportional to the duration of diabetes mellitus. Some studies found no correlation between severity of diabetes and hearing $\operatorname{loss}^{(7)}$ whereas some of them have demonstrated a positive correlation between severity of diabetes and hearing loss. $(5,10)$ In the current study, fasting blood sugar was used as 
a measure and correlated with hearing status. However, various researchers have used different parameters of blood sugar status while correlating the hearing thresholds such as HbA1c level(10) and fructosamine levels. (7)

In the literature, a correlation was found between hearing levels and age of the subjects in the diabetic groups. In the present study, cases belong to age between 30 and 50 years with a mean age of 42 years. The hearing loss due to diabetes could be attributed to age alone.(2) However, a study done by Panchu(6) showed the effect of age on auditory thresholds of diabetic patients was statistically insignificant.

From this study, it is noted that the gender did not have an effect on hearing status. Relationship between hearing threshold and gender has been quoted differently by various studies. No correlations between hearing impairment and gender was seen in some studies. $(5,10)$ However, in some study, female diabetics had a higher hearing threshold as compared to males. $(2,3)$

With respect to the effect of the duration of diabetes on hearing threshold, different authors have shown variable associations, some found a positive correlation between duration of diabetes and hearing loss(2) and others found no association. $(3,6,10)$ In the current study, there is a strong correlation between the duration of diabetes mellitus and sensorineural hearing loss. Those who are having more than 15 years of diabetes mellitus had a prevalence of sensorineural hearing loss (78.9\%). The newly diagnosed diabetics and those known diabetics whose duration of illness was less or equal to 5 years had a prevalence of only $10.6 \%$. The duration of diabetes mellitus is a significant factor responsible for sensorineural hearing loss in diabetics. In a study conducted by Sheetal Krishnappa et al ${ }^{(8)}$, the incidence of hearing loss was $63 \%$ in diabetics of less than 10 years of duration as compared to $85 \%$ hearing loss in diabetics of 10 years of duration. Further, as duration progressed the severity of hearing loss also increased in most of the cases.(8)

\section{Summary}

Present study is a hospital based cross sectional study conducted on 200 diabetic patients attending medicine OPD during the period March 2014 to March 2015. These patients were recruited to ENT Department for clinical and audiological evaluation.

Diabetic patients aged between 30 and 55 years were included in the study. Mean age was 42.51 years, S.D. $=7.49$ years. The prevalence of SNHL in the study group was $34.5 \%$.

The prevalence was more in older age group (46-55 years age, $58.2 \%$ ) than younger age group (30-38 years age, $14.9 \%$ ). Severity of SNHL was also high among older age group.

The prevalence was almost comparable between males and females. Males were $31.5 \%$ and Females were $39.5 \%$.

It was found that greater the duration of diabetes greater is the prevalence of SNHL. In less than 5 years duration group, prevalence was $10.6 \%$. In 5 to 10 years duration group, prevalence was $38.6 \%$. In 10 to 15 years duration group, prevalence was $69.2 \%$. In more than 15 years duration group, it was $78.9 \%$. Severity of SNHL was also high among the cases with greater duration of DM.

The prevalence of SNHL was more in patients having uncontrolled diabetic status (94.6\%) compared to patients having controlled diabetic status (20.9\%). Severity was also high among uncontrolled diabetic group.

\section{CONCLUSIONS}

1. The prevalence of SNHL in diabetic patients is $34.5 \%$.

2. There is an increase in the prevalence of SNHL as the age of the diabetic patient increases.

3. Severity of SNHL also increases with age of the diabetics.

4. Sex has no effect on the prevalence of SNHL among diabetic patients.

5. Greater the duration of DM greater will be the prevalence of SNHL.

6. Greater the duration of DM higher will be the severity of SNHL.

7. Uncontrolled diabetic status has an increased prevalence of SNHL.

8. Severity of SNHL is high among uncontrolled diabetic group compared to controlled diabetic group.

\section{REFERENCES}

1. Anjana RM, Ali MK, Pradeepa R, et al. The need for obtaining accurate nationwide estimates of diabetes prevalence in India-rationale for a national study on diabetes. Indian J Med Res 2011:133(4):369-80.

2. Taylor IJ, Irwin J. Some audiological aspects of diabetes mellitus. J Laryngol Otol 1978;92(2):99-113.

3. Cullen JR, Cinnamond MJ. Hearing loss in diabetics. J Laryngol Otol 1993;107(3):179-82.

4. Harner SG. Hearing in adult-onset diabetes mellitus. Otolaryngol Head Neck Surg 1981;89(2):322-7.

5. EL-Tabal ES, Mackenzie I, Surenthiren SS, et al. The relationship of hearing loss to age, duration, degree of control and complications in diabetic patients. Audiol Med 2003;1(4):242-6.

6. Panchu P. Auditory acuity in patients with type 2 diabetes mellitus. Int J Diabetes Dev Ctries 2008;28(4):114-20.

7. Asma A, Azmi MN, Mazita A, et al. A single blinded randomized controlled study of the effect of conventional oral hypoglycemic agents versus intensive short- term insulin therapy on pure tone audiometry in type 2 diabetes mellitus. Indian J Otolaryngol Head Neck Surg 2011;63(2):114-8.

8. Krishnappa S, Naseeruddin K. A clinical study of age related hearing loss among diabetes patients. Indian Journal of Otology 2014;20(4):160-5.

9. Qaiyum HA, Tamkanth A, Siraj M, et al. A study on the incidence of sensorineural hearing loss in patients with diabetes mellitus. International Journal of Advanced Research 2015;3(2):685-7.

10. Agarwal AC, Pujary K, Ganapathy K, et al. Pure tone audiometry and otoacoustic emissions for the assessment of hearing loss in diabetic patients. Indian Journal of Otology 2013;19(1):13-17.

11. American Diabetes Association. Standards of medical care in diabetes-2007. Diabetes Care 2007;30 (Suppl 1):S4-S41.

12. Chamyal PC. Vestibulocochlear functions in diabetes mellitus. Journal of Otology and Head \& Neck Surgery 1997;49(2):162-64.

13. Kakarlapudi V, Sawyer R, Staecker $H$. The effect of diabetes on sensorineural hearing loss. Otology Neurotology 2003;24(3):382-6. 